\title{
Acute Blockade of Nitric Oxide Synthase Inhibits Renal Vasodilation and Hyperfiltration During Pregnancy in Chronically Instrumented Conscious Rats
}

\author{
L. A. Danielson* and K. P. Conrad ${ }^{\star *}$ \\ *Department of Physiology, University of New Mexico School of Medicine, Albuquerque, New Mexico 87131; and ${ }^{\ddagger}$ Magee-Womens \\ Research Institute, Department of Obstetrics, Gynecology and Reproductive Sciences, University of Pittsburgh, Pittsburgh, \\ Pennsylvania 15213
}

\begin{abstract}
Because the kidneys are vasodilated and the endogenous production of nitric oxide is increased in gravid rats, we tested whether nitric oxide mediates the renal vasodilatory response to pregnancy. Chronically instrumented, conscious rats of gestational days 12-14 were studied concurrently with age-matched virgin control animals. GFR and effective renal plasma flow (ERPF) were determined by the renal clearances of inulin and para-aminohippurate before and during acute infusion of $\mathbf{N \omega}$-nitro-L-arginine methyl ester (NAME; 2, 20, and $50 \mu \mathrm{g} / \mathrm{min}$ ) or $N^{\mathrm{G}}$-monomethyl-L-arginine $(100 \mu \mathrm{g} / \mathrm{min})$. Baseline GFR and ERPF were significantly increased, and effective renal vascular resistance was decreased by $30-40 \%$ in gravid rats compared with virgin controls. During infusion of all three dosages of NAME and $N^{\mathrm{G}}$-monomethyl-L-arginine, effective renal vascular resistance, GFR, and ERPF were equalized in the pregnant and virgin rats (the only exception being GFR during the 20 $\mu \mathrm{g} / \mathrm{min}$ NAME infusion). When compared with virgin rats, the gravid animals were more responsive to nitric oxide synthase inhibition, showing a significantly greater decline in GFR and ERPF and rise in effective renal vascular resistance at each timepoint during the infusion of inhibitor. To exclude the possibility that nonspecific renal vasoconstriction per se led to equalization of renal function in the two groups of rats, we investigated angiotensin II. In contrast to the results observed with nitric oxide synthase inhibitors, pregnant rats were less responsive to the renal vasoconstrictory effects of angiotensin II, such that the baseline differences in renal parameters measured before infusion of the hormone were increased during the infusion. To determine whether nitric oxide synthase was inhibited to a similar extent in gravid and virgin rats, aortic and renal cortical cGMP content was assayed ex vivo at the end of inhibitor infusion. The lower $2-\mu \mathrm{g} / \mathrm{min}$ dose of NAME consistently reduced cGMP content of these tissues to comparable levels in the two groups of rats. In conclusion, we suggest that
\end{abstract}

Portions of this work were published in abstract form (1994. J. Am. Soc. Nephrol. 5:576, and Society for Gynecologic Investigation, 42nd Annual Meeting, 1995, In press). This work served to partly fulfill the requirements of the Ph.D. degree for L. A. Danielson.

Address correspondence to Kirk P. Conrad, M.D., Magee-Womens Research Institute, 204 Craft Avenue, Pittsburgh, PA 15213. Phone 412 641-6003; FAX: 412-641-1503.

Received for publication 20 December 1994 and accepted in revised form 14 March 1995.

J. Clin. Invest.

(c) The American Society for Clinical Investigation, Inc. $0021-9738 / 95 / 07 / 0482 / 09 \quad \$ 2.00$

Volume 96, July 1995, 482-490 nitric oxide mediates reduced renal vascular resistance and hyperfiltration during pregnancy in conscious rats. ( J. Clin. Invest. 1995. 96:482-490.) Key words: renal blood flow • glomerular filtration rate $\bullet$ renal vascular resistance $\bullet$ angiotensin II • cyclic guanosine-3', $\mathbf{5}^{\prime}$-monophosphate

\section{Introduction}

Profound vasodilation of the maternal circulation typifies normal human gestation. The renal vascular bed participates in this vasodilatory response to pregnancy. Both renal blood flow and glomerular filtration rate peak at $40-80 \%$ above preconception values during the late first or early second trimester (reviewed in reference 1). Moreover, renal blood flow rises in the face of a 5- to $10-\mathrm{mmHg}$ decline in blood pressure (2), underscoring the marked fall in renal vascular resistance that occurs during human pregnancy. The chronically instrumented conscious rat undergoes alterations in renal function during pregnancy that are comparable with those observed in gravid women. Both glomerular filtration rate and renal blood flow increase in early pregnancy and peak during midgestation at $20-40 \%$ above preconception values (3). Like human pregnancy, the rise in renal blood flow and glomerular filtration rate is secondary to a fall in renal vascular resistance. Although renal vasodilation in pregnancy is likely to be under endocrinologic control, the hormones or autocoids involved remain unknown. In this regard, earlier work demonstrated that vasodilatory prostaglandins are unlikely to mediate the renal hemodynamic changes of rat pregnancy (4-6).

Other endothelial-derived vasodilators, however, may be involved. We postulated that the elevated plasma level, urinary excretion, and "metabolic production" of cGMP observed in rat gestation reflect enhanced biosynthesis of endothelium-derived relaxing factor or nitric oxide $(7,8)$. This hypothesis has been recently substantiated (9). Because the kidneys are vasodilated in gravid rats and the endogenous production of nitric oxide is increased, we tested whether nitric oxide mediates the renal vasodilatory response to pregnancy. Demonstration of a critical role for nitric oxide in the maternal vasodilatory responses of normal pregnancy would strengthen the hypothesis that deficient nitric oxide production contributes to vasoconstriction of the kidney and other vascular beds in preeclampsia.

\section{Methods}

Animal preparation. Female Long-Evans rats aged 12-14 wk were purchased from Harlan Sprague-Dawley (Indianapolis, IN) and fed Harlan Teklad Rodent Chow \#8604 containing $0.31 \%$ sodium. The rats were habituated to a Plexiglas restraining cage on at least five different occasions, each lasting several hours, before surgical preparation. This experimental cage was especially designed to accomodate the swollen abdomen of gravid rats and to allow for grooming of the face and front paws while preventing the rat from turning around. Thus, accurate timed 
urine collections were possible via the chronically implanted bladder catheter (see below). Rats that failed to habituate to the cage ( $<5 \%$ of all animals) were eliminated from the study. Details of the surgical procedure have been previously described $(3,4)$.

In brief, under ketamine $(6.0 \mathrm{mg} / 100 \mathrm{~g}$ body weight $)$ and pentobarbital sodium ( $2.1 \mathrm{mg} / 100 \mathrm{~g}$ body weight) anesthesia, Tygon catheters ( 0.015 in ID, 0.030 in OD; Norton, Akron, $\mathrm{OH}$ ) were implanted in the abdominal aorta and inferior vena cava via the femoral artery and vein, respectively. The tips of these catheters lay below the level of the renal vessels. The catheters were then routed subcutaneously, exteriorized between the scapulae, filled with a dextrose-heparin mixture, and plugged with stainless steel pins. A cannula of silastic-covered stainless steel was then sewn into the urinary bladder with a purse string suture and exteriorized through the ventral abdominal wall. The bladder cannula was stoppered with a silastic-covered 18-gauge pin so that the rat voided through the urethra while in her home cage. During experiments, the obturator was removed for urine collection. All surgical procedures were performed using aseptic technique. The rats were housed individually after surgery and allowed a minimum of $7 \mathrm{~d}$ of recovery. The vascular catheters were then allowed to slip beneath the skin in all of the animals. They were next randomly divided into two groups. One group, destined to become pregnant, was housed with male rats. The other group was not mated and served as age-matched virgin control animals. The presence of spermatozoa in the vaginal lavage marked day 0 of gestation (term pregnancy, $22 \mathrm{~d}$ ). On gestational days 4-5, a third catheter was implanted in the right jugular vein and the other vascular catheters were reexteriorized under anesthesia. The virgin control rats underwent the same procedures. Renal function experiments were then conducted on gestational days $12-14$, when changes in renal hemodynamics and glomerular filtration rate are maximal in this species (3).

Experimental protocol. For each experiment, a midterm pregnant and age-matched virgin control rat were placed in experimental cages and studied concurrently. The arterial catheter of each rat was connected to a Gould P23 ID pressure transducer (Statham Instrument, Hato Rey, Puerto Rico) and a Gould Universal amplifier. Phasic and mean blood pressures were displayed on two channels of a Gould 3000 series chart recorder. This catheter was also used for collection of blood samples. The jugular venous catheter was used to administer a priming bolus followed by constant infusion of inulin and para-aminohippurate at a flow rate of $10 \mu 1 / \mathrm{min}$ delivered by a Sage infusion pump (model 355; Orion Research, Cambridge, MA). The femoral venous catheter was connected to another Sage infusion pump for administration of nitric oxide synthase inhibitors or angiotensin II at a flow rate of $10 \mu \mathrm{l} /$ min. Finally, the bladder cannula was extended with a short piece of polyethylene tubing, and timed urine collections were made. This technique of urine collection proved to be reliable, because after reaching steady-state conditions, the excretion rates of inulin and para-aminohippurate were $97 \pm 2$ and $97 \pm 2 \%$ of their respective infusion rates for virgin rats $(n=47)$ and $93 \pm 2$ and $94 \pm 2 \%$ for the gravid rats $(n=47)$. The renal clearance of inulin and para-aminohippurate thus provided an accurate measure of GFR and effective renal plasma flow, respectively.

After the priming dose and constant infusion of inulin $(0.2 \mathrm{ml} / 100$ $\mathrm{g}$ body weight of $10 \%$ inulin, $0.25 \mathrm{mg} / \mathrm{min} \cdot 100 \mathrm{~g}$ body weight ${ }^{-1}$ ) and para-aminohippurate $(0.2 \mathrm{ml} / 100 \mathrm{~g}$ body weight of $1 \%$ para-aminohippurate, $0.05 \mathrm{mg} / \mathrm{min} \cdot 100 \mathrm{~g}$ body weight $^{-1}$ ) were administered, an equilibration period of $60 \mathrm{~min}$ was allowed for the compounds to reach steady-state plasma concentration. Then, three 30-min urine collections were made with midpoint blood samples ( $200 \mu \mathrm{l}$ each). After centrifugation of blood samples and separation of plasma from cells, the latter were resuspended in Ringer's solution and returned to the rat. Infusion of $N \omega$-nitro-L-arginine methyl ester (NAME ${ }^{1}$, Sigma Chemical, St. Louis MO) $\mathrm{HCl}(2,20$, or $50 \mu \mathrm{g} / \mathrm{min}), N^{\mathrm{G}}$-monomethyl-L-arginine (NMA, Calbiochem, La Jolla, CA) monoacetate (100 $\mu \mathrm{g} / \mathrm{min})$ or angiotensin

1. Abbreviations used in this paper: ERPF, effective renal plasma flow; ERVR, effective renal vascular resistance; MAP, mean arterial pressure; NAME, $N \omega$-nitro-L-arginine methyl ester; NMA, $N^{\mathrm{G}}$-monomethyl-Larginine.
II ( $3 \mathrm{ng} / \mathrm{min}$ ) was next begun. After another 60 -min equilibration period by which time blood pressure had stabilized, four additional 30-min renal clearances were conducted. After the last renal clearance period, the rats were anesthetized with pentobarbital sodium $(6 \mathrm{mg} / 100 \mathrm{~g}$ body weight), and the aorta and kidneys were rapidly excised, rinsed in cold PBS, flash frozen in liquid nitrogen, and stored at $-80^{\circ} \mathrm{C}$ until assay for cGMP. Time-control experiments showing the stability of renal hemodynamics and glomerular filtration rate in this rat preparation have been previously published by us $(4,10)$.

Tissue cGMP. A 2-cm length of aorta was homogenized in $1.0 \mathrm{ml}$ of ice-cold $0.6 \mathrm{~N}$ perchloric acid. After centrifugation at $3,000 \mathrm{~g}$ for 10 min at $4^{\circ} \mathrm{C}$, the pellet was frozen at $-20^{\circ} \mathrm{C}$ for determination of protein The supernatant was neutralized with $5.0 \mathrm{~N} \mathrm{KOH}$. After another centrifugation to pellet the $\mathrm{KClO}_{4}$, the supernatant was frozen at $-20^{\circ} \mathrm{C}$ for subsequent measurement of cGMP by radioimmunoassay. Identical procedures were used to process two $0.5-\mathrm{mm}$ slices of renal cortex taken from each kidney with a Stadie-Riggs microtome (Thomas Scientific). Procedural losses were monitored for each tissue homogenization by adding tracer amounts of $\left[{ }^{3} \mathrm{H}\right] \mathrm{cGMP}(1,400 \mathrm{cpm})$ to the perchloric acid. Each result was corrected accordingly. Recovery averaged $69 \pm 1 \%$.

Preparation of drugs. NAME $\mathrm{HCl}$ and NMA monoacetate salt were freshly prepared in Ringer's solution for each experiment. Angiotensin II (5-ILE ANG II or Hypertensin II, Sigma Chemical) was prepared as a $100-\mu \mathrm{g} / \mathrm{ml}$ stock solution in $5 \%$ dextrose and frozen in aliquots at $-20^{\circ} \mathrm{C}$. For each experiment, working solutions were prepared in Ringer's solution. Inulin ( $5 \mathrm{~g} / 50 \mathrm{ml}$, Isotex, Friendswood, TX) was stored in 15-ml aliquots at $4^{\circ} \mathrm{C}$. For each experiment, an aliquot was placed in a boiling water bath until fully dissolved, usually for $3 \mathrm{~min}$. It was then diluted along with para-aminohippurate (20\% sodium hippurate, Merck, Sharpe and Dohme, West Point, PA) in Ringer's solution for infusion.

Analytical techniques. Inulin in plasma and urine was measured by the anthrone method (11) and para-aminohippurate by the method of Bratten and Marshall as modified by Smith et al. (12). Urine volume was determined gravimetrically. All renal clearance data have been expressed per whole animal. Radioimmunoassay of cGMP was performed as previously reported and validated (7-9). Tissue proteins were measured by the Bradford technique (13).

Statistical analysis. Data are presented as means \pm SEM. Differences in baseline parameters between virgin and midterm pregnant rats (Table I) were analyzed by unpaired Student's $t$ tests. All other data were analyzed by two-factor univariate ANOVA. If significant main effects were observed, then individual group means were contrasted by the Tukey test (14). $P<0.05$ was taken to be significant.

\section{Results}

Table I summarizes baseline values for all of the virgin and midterm pregnant rats studied. In particular, both GFR and effective renal plasma flow (ERPF) were significantly increased by $30-40 \%$ in the gravid rats when compared with virgin control animals. Furthermore, effective renal vascular resistance (ERVR) was significantly decreased by a similar degree in the pregnant animals.

The impact of nitric oxide synthase inhibition on renal function and blood pressure using the arginine analogue, NAME, is depicted in Figs. 1 and 2. Averaged results are shown in Fig. 1. With each dosage of NAME, blood pressure significantly increased in midterm pregnant and virgin rats reaching a plateau after $60 \mathrm{~min}$ of infusion. With the lowest dosage of NAME ( 2 $\mu \mathrm{g} / \mathrm{min}$ ), mean arterial pressure (MAP) rose by $5-10 \mathrm{mmHg}$, whereas the highest dosage ( $50 \mu \mathrm{g} / \mathrm{min})$ produced elevations of $30-40 \mathrm{mmHg}$. Before infusion of the nitric oxide synthase inhibitor, GFR and ERPF were greater and ERVR was less in the gravid rats when compared with the virgin animals ( $P$ $<0.01$ ). During infusion of each of the three doses of NAME, these renal parameters were equalized in the two groups of rats. 
Table I. Summary of Baseline Values for Virgin and Pregnant Rats

\begin{tabular}{|c|c|c|c|c|c|c|c|c|}
\hline & MAP & GFR & ERPF & ERVR & FF & Hct & Body Weight & No. fetuses \\
\hline & $m m H g$ & $\mu / / \min$ & $\mu l$ min & $m m H g / m l \cdot m^{-1}$ & $\%$ & $\%$ & $g$ & \\
\hline Virgin rats $(n=47)$ & $113 \pm 1$ & $2176 \pm 38$ & $7075 \pm 125$ & $9.5 \pm 0.2$ & $31 \pm 1$ & $42 \pm 0$ & $283 \pm 4$ & - \\
\hline Pregnant rats $(n=47)$ & $112 \pm 1^{*}$ & $2825 \pm 52 *$ & $9934 \pm 154 *$ & $6.5 \pm 0.1 *$ & $28 \pm 1^{*}$ & $39 \pm 0^{*}$ & $316 \pm 4 *$ & $8 \pm 2$ \\
\hline
\end{tabular}

${ }^{*} P<0.05$ pregnant vs. virgin by unpaired Student's $t$ tests. FF, filtration factor; Hct, hematocrit.

(An exception, which we are at a loss to explain, is GFR during the $20-\mu \mathrm{g} / \mathrm{min}$ infusion). Fig. 2 depicts the time course of change in GFR, ERPF, and ERVR during the $2-\mu \mathrm{g} / \mathrm{min}$ NAME infusion and highlights the reason for normalization of renal function in gravid rats. The midterm pregnant rats were more responsive to nitric oxide synthase inhibition, showing a greater decline in GFR and ERPF and rise in ERVR at each time point during the infusion of inhibitor compared with virgin animals. Similar time course curves were observed for the other dosages of NAME (data not shown). Before infusion of NAME, filtration fraction was $31 \pm 1$ and $28 \pm 1 \%$ in virgin and gravid rats, respectively $(P<0.05)$. During infusion of 2 and $20 \mu \mathrm{g} / \mathrm{min}$ NAME, filtration fraction rose to $41 \pm 2 \%$ and $47 \pm 2 \%$ in both groups of rats, respectively; at $50 \mu \mathrm{g} / \mathrm{min}$, filtration was $53 \pm 2 \%$ for virgin rats and $51 \pm 3 \%$ for the gravid animals.

To substantiate these results using NAME, we investigated another nitric oxide synthase inhibitor, NMA (Table II and Fig. 3 ). Inspection of the time course data (Fig. 3) reveals that the midterm pregnant rats were more responsive to inhibition of nitric oxide synthase with NMA, as they showed a greater decline in GFR and ERPF and rise in ERVR than virgin control animals. Thus, GFR, ERPF, and ERVR were equalized during the $100-\mu \mathrm{g} / \mathrm{min}$ infusion of NMA (Table II).

To exclude the possibility that nonspecific renal vasoconstriction per se led to equalization of renal function in gravid and virgin rats, we tested the response to angiotensin II. Table III and Fig. 4 depict the average and time course, respectively, of blood pressure and renal responses to the vasoconstrictor hormone infused at $3 \mathrm{ng} / \mathrm{min}$. MAP rose by $30-40 \mathrm{mmHg}$ in both groups of rats. In contrast to the results obtained with nitric oxide synthase inhibitors, the pregnant rats were less responsive to the vasoconstrictory effects of angiotensin II (Fig. 4), such
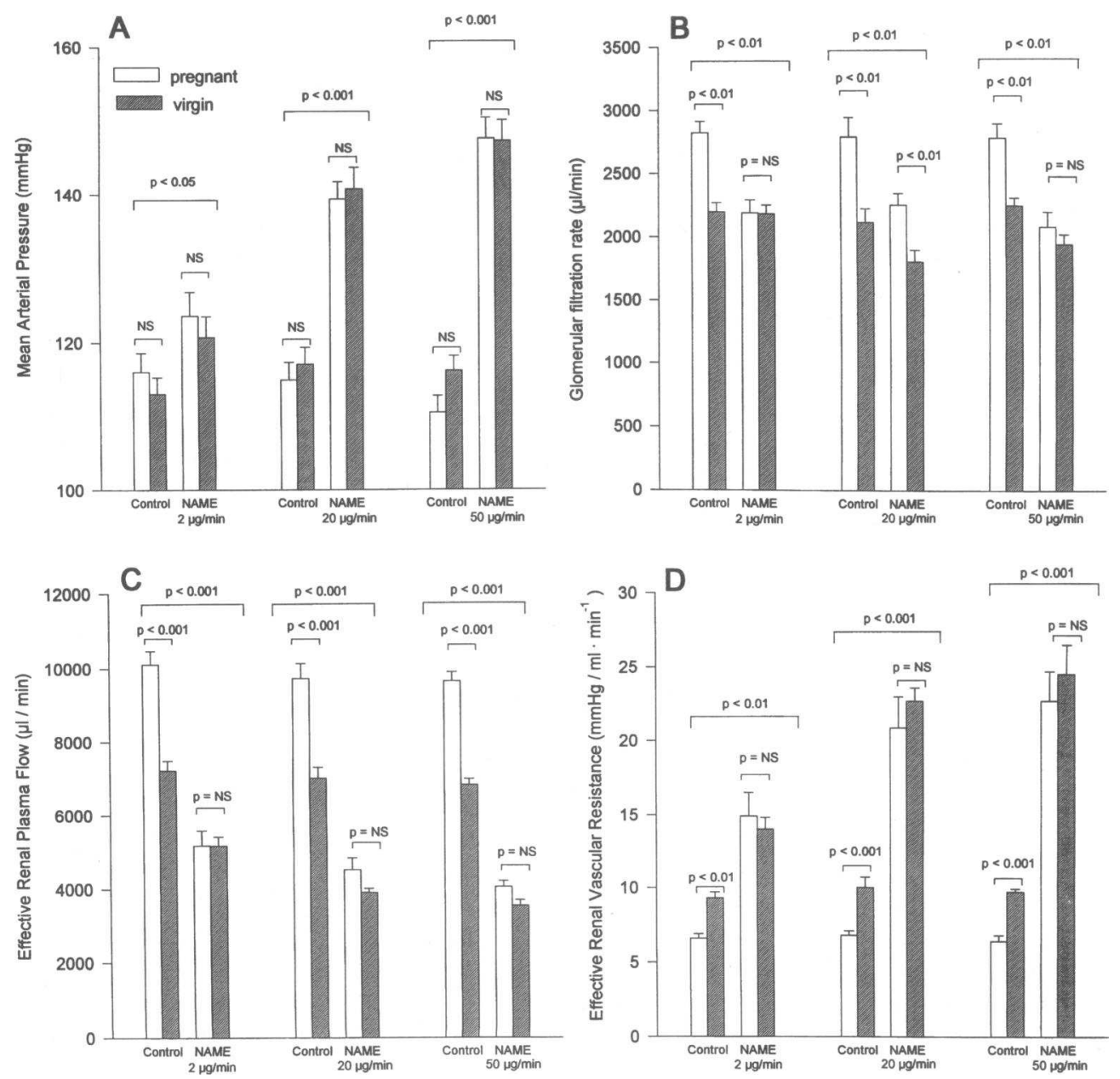

Figure 1. Effect of NAME on $\operatorname{MAP}(A), \operatorname{GFR}(B), \operatorname{ERPF}(C)$, and ERVR $(D)$ in midterm pregnant ( $\square$ ) and virgin control ( $(\square)$ 
A mume (Rvoming)

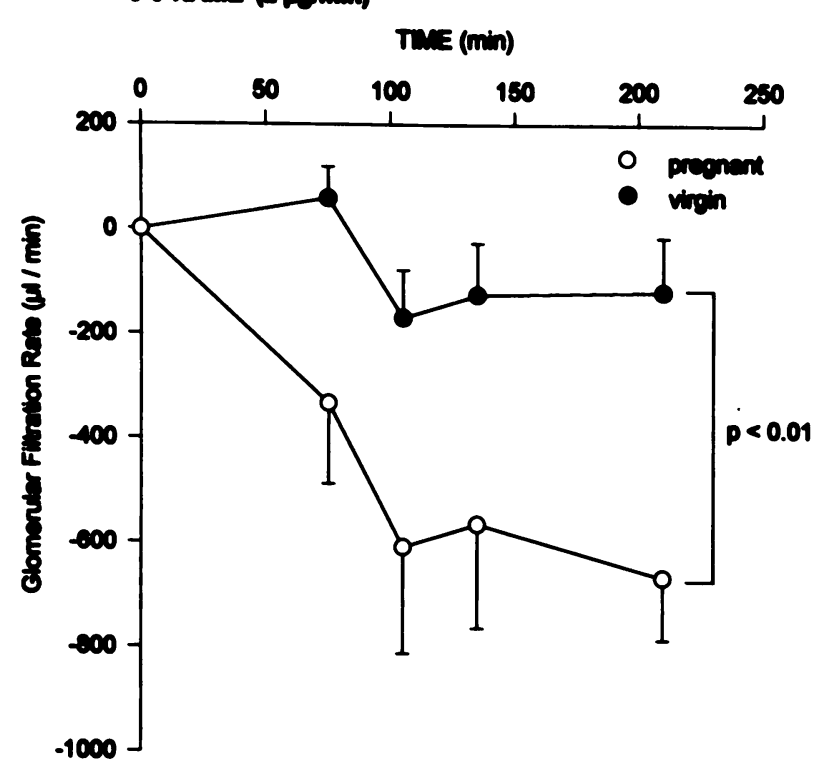

C

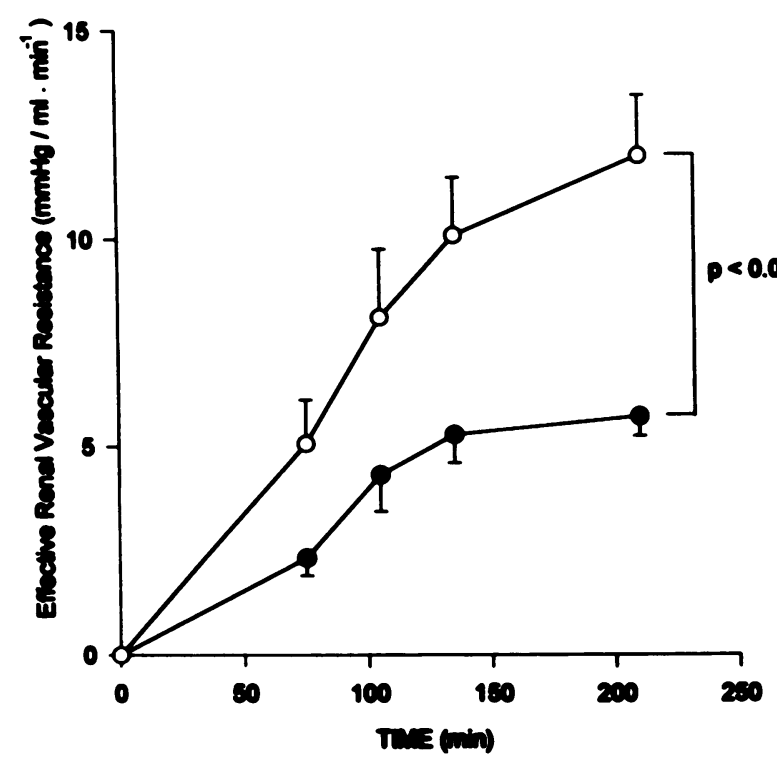

$\mathbf{B}$

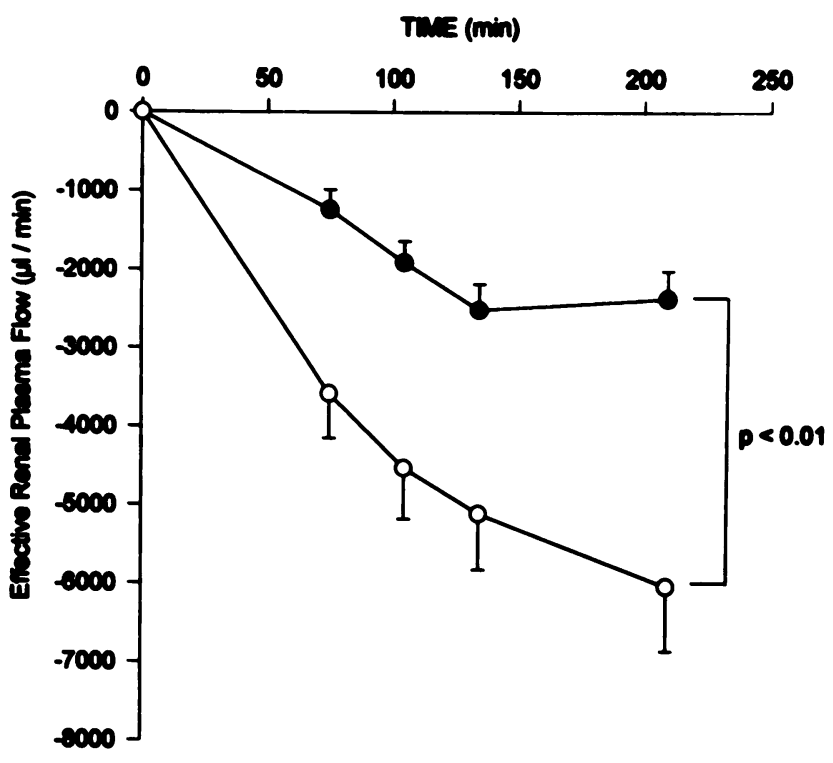

Figure 2. Effect of NAME over time on the change in GFR $(A)$, ERPF $(B)$, and ERVR $(C)$ in midterm pregnant $(O)$ and virgin control $(\bullet)$ rats.

Table II. Effect of Intravenous Infusion of NMA on Blood Pressure and Renal Function in Conscious Virgin and Pregnant rats

\begin{tabular}{|c|c|c|c|c|}
\hline & \multicolumn{2}{|c|}{ Control } & \multicolumn{2}{|c|}{$100 \mu \mathrm{g} / \min$ NMA } \\
\hline & Virgin & Pregnant & Virgin & Pregnant \\
\hline Mean arterial pressure $(\mathrm{mmHg})$ & $115 \pm 2$ & $108 \pm 1^{*}$ & $138 \pm 4$ & $130 \pm 4$ \\
\hline GFR $(\mu \mathrm{l} / \mathrm{min})$ & $2,144 \pm 108$ & $2,772 \pm 105^{\ddagger}$ & $1,963 \pm 166$ & $2,119 \pm 98$ \\
\hline Effective renal plasma flow $(\mu 1 / \mathrm{min})$ & $7,500 \pm 377$ & $9,928 \pm 411^{\ddagger}$ & $5,409 \pm 278$ & $5,981 \pm 348$ \\
\hline Filtration fraction $(\%)$ & $29 \pm 2$ & $28 \pm 2$ & $37 \pm 3$ & $35 \pm 1$ \\
\hline Effective renal vascular resistance $\left(\mathrm{mmHg} / \mathrm{ml} \cdot \mathrm{min}^{-1}\right)$ & $8.8 \pm 0.5$ & $6.3 \pm 0.4^{\ddagger}$ & $14.0 \pm 1.2$ & $13.3 \pm 1.0$ \\
\hline
\end{tabular}

Eight virgin and midterm pregnant rats were tested. ${ }^{*} P<0.05,{ }^{\ddagger} P<0.01$ pregnant vs. virgin by Tukey test. 


\section{A men (100 vormm)}

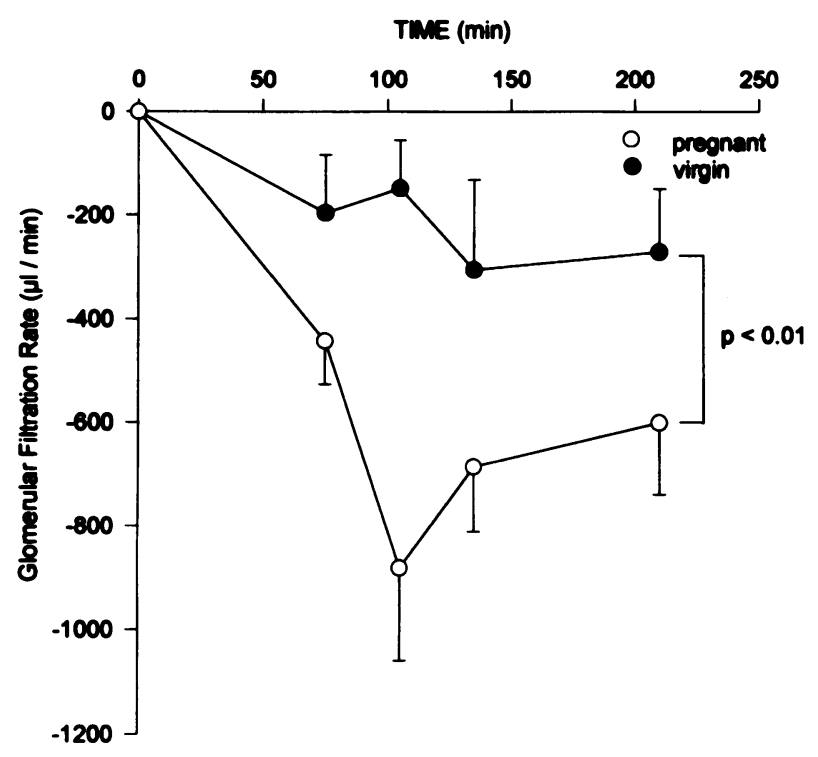

C

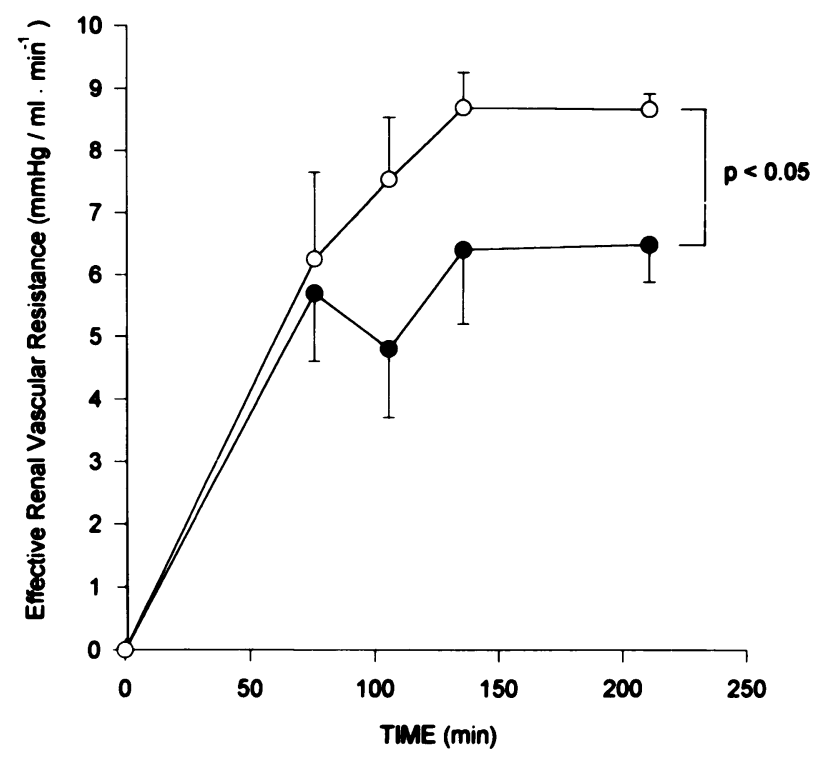

B

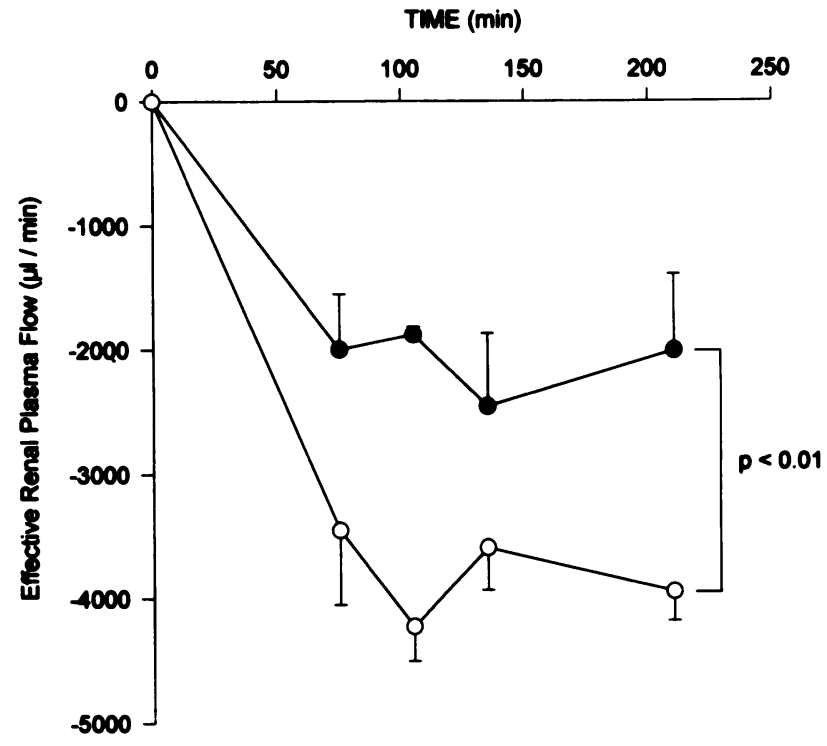

Figure 3. Effect of NMA over time on the change in GFR $(A), \operatorname{ERPF}(B)$, and ERVR $(C)$ in midterm pregnant $(O)$ and virgin control $(\bullet)$ rats.

Table III. Effect of Intravenous Infusion of Angiotensin II on Blood Pressure and Renal Function in Conscious Virgin and Pregnant Rats

\begin{tabular}{|c|c|c|c|c|}
\hline & \multicolumn{2}{|c|}{ Control } & \multicolumn{2}{|c|}{$3 \mathrm{ng} / \mathrm{min}$ Angiotensin II } \\
\hline & Virgin & Pregnant & Virgin & Pregnant \\
\hline Mean arterial pressure $(\mathrm{mmHg})$ & $112 \pm 2$ & $107 \pm 3$ & $132 \pm 3$ & $130 \pm 2$ \\
\hline GFR $(\mu 1 / \min )$ & $2,228 \pm 126$ & $3,008 \pm 142^{*}$ & $1,841 \pm 128$ & $2,713 \pm 226^{*}$ \\
\hline Effective renal plasma flow $(\mu \mathrm{l} / \mathrm{min})$ & $7,015 \pm 405$ & $10,578 \pm 383^{\ddagger}$ & $4,143 \pm 256$ & $8,878 \pm 293^{\ddagger}$ \\
\hline Filtration fraction $(\%)$ & $32 \pm 2$ & $29 \pm 2$ & $45 \pm 3$ & $31 \pm 3^{\ddagger}$ \\
\hline Effective renal vascular resistance $\left(\mathrm{mmHg} / \mathrm{ml} \cdot \mathrm{min}^{-1}\right)$ & $9.6 \pm 0.7$ & $5.9 \pm 0.2^{\ddagger}$ & $19.5 \pm 1.4$ & $9.9 \pm 1.0^{\ddagger}$ \\
\hline
\end{tabular}

Six virgin and midterm pregnant rats were studied. ${ }^{*} P<0.01,{ }^{\ddagger} P<0.001$ pregnant vs. virgin by Tukey test. 

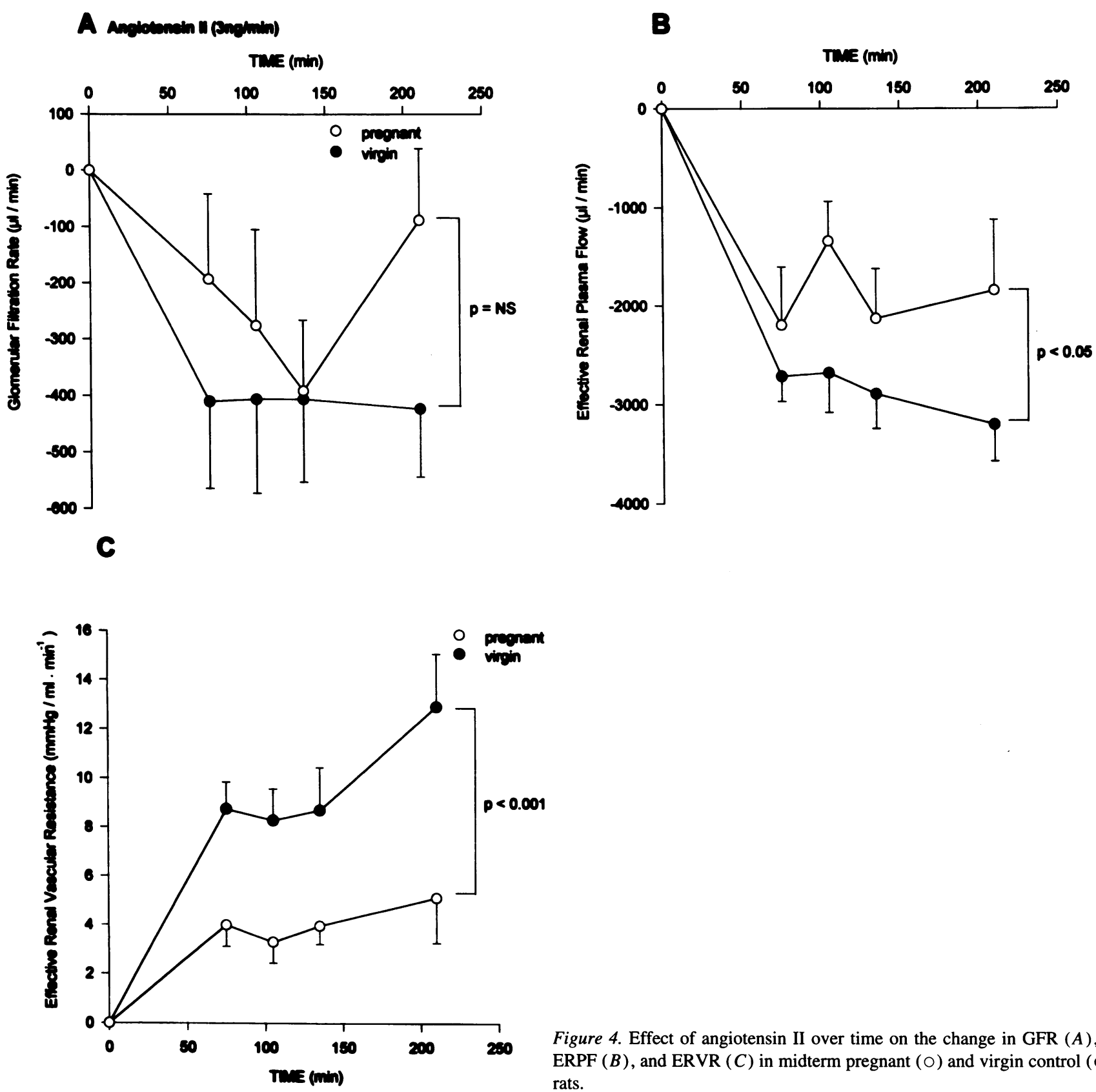

Figure 4. Effect of angiotensin II over time on the change in GFR $(A)$, ERPF $(B)$, and ERVR $(C)$ in midterm pregnant $(O)$ and virgin control $(\bullet)$ rats.

that baseline differences in renal parameters measured before infusion of the hormone were magnified during the infusion (Table III).

To determine whether nitric oxide synthase was inhibited to a similar extent in the gravid and virgin rats, we killed the animals at the end of the inhibitor infusion and assayed cGMP content in the aorta and kidney cortex ex vivo (Table IV). Because cGMP is a second messenger molecule of nitric oxide generated by soluble guanylate cyclase, we measured tissue cGMP levels as a sensitive bioassay of nitric oxide activity. Additional virgin and pregnant rats were used to provide control values. Baseline cGMP content of aorta and kidney cortex was not significantly different between the two groups of rats. The lower $2-\mu \mathrm{g} / \mathrm{min}$ dose of NAME consistently reduced cGMP content of aorta and kidney to comparable levels in the midterm pregnant and virgin rats.

\section{Discussion}

Most mammalian species, including the rat and the human, manifest renal vasodilation and hyperfiltration during pregnancy (reviewed in references 1 and 7). In the present study, we corroborated these findings for conscious gravid rats (Table I). Because endogenous production of nitric oxide and its second messenger, cGMP, are increased during gestation in rats (79), we reasoned that this potent vasodilatory system may mediate renal vasodilation and hyperfiltration of pregnancy. The objective of the present work, therefore, was to test this hypothesis. The major findings were as follows: $(a)$ several dosages of the nitric oxide synthase inhibitor, NAME, acutely equalized effective renal plasma flow and renal vascular resistance, as well as glomerular filtration rate in gravid and virgin rats; $(b)$ identical results were obtained with a structurally different nitric 


\begin{tabular}{|c|c|c|c|c|c|}
\hline & \multirow[b]{2}{*}{ Control } & \multicolumn{3}{|c|}{ Name } & \multirow[b]{2}{*}{ NMA $(100 \mu \mathrm{g} / \mathrm{min})$} \\
\hline & & $2 \mu \mathrm{g} / \mathrm{min}$ & $20 \mu \mathrm{g} / \mathrm{min}$ & $50 \mu \mathrm{g} / \mathrm{min}$ & \\
\hline \multicolumn{6}{|l|}{ Virgin rats } \\
\hline Aorta & $3,370 \pm 380$ & $1,289 \pm 207 *$ & $3,071 \pm 469$ & $1,722 \pm 179^{*}$ & $775 \pm 114^{*}$ \\
\hline Kidney & $1,636 \pm 242$ & $431 \pm 92^{*}$ & $2,482 \pm 173$ & $553 \pm 91 *$ & $1,231 \pm 112$ \\
\hline \multicolumn{6}{|c|}{ Pregnant rats } \\
\hline Aorta & $2,428 \pm 454$ & $901 \pm 231 *$ & $2,762 \pm 274$ & $2,211 \pm 304$ & $1,495 \pm 281$ \\
\hline Kidney & $1,484 \pm 135$ & $382 \pm 32 *$ & $1,684 \pm 407$ & $747 \pm 235^{*}$ & $1,398 \pm 209$ \\
\hline
\end{tabular}

Tissues were harvested from five to seven rats for the control values and for each dosage of NAME and NMA. $* P<0.05$ vs. control by Tukey test. There was no significant difference in aortic or renal cGMP content between virgin and pregnant rats in the control condition and after nitric oxide synthase blockade.

oxide synthase inhibitor, NMA; $(c)$ aortic and renal cGMP content was reduced to comparable levels in virgin and gravid rats ex vivo (consistently so with the low dosage of NAME, see below), indicating that comparable inhibition of nitric oxide synthase was reached during infusion of the inhibitor in the two groups of animals; and $(d)$ infusion of angiotensin II magnified the baseline differences in renal hemodynamics and GFR between virgin and gravid rats, demonstrating that the equalization of these parameters after nitric oxide synthase inhibition was not merely a consequence of nonspecific renal vasoconstriction.

Various potential mechanisms for gestational changes in renal function have been previously raised and tested. Marked expansion of extracellular and plasma volume occurs during gestation in most mammalian species, including rodents and humans $(15,16)$. This expansion, however, does not correlate well with the changes in renal function. It is minimal during early gestation when ERPF and GFR are rapidly increasing and is maximal during late pregnancy when ERPF and GFR are more or less stable. Nevertheless, plasma volume expansion may contribute to the gestational changes in renal hemodynamics and GFR. Baylis and co-workers (17) tested the effects of acute expansion of plasma volume in conscious virgin female rats and found that it had little impact on GFR and ERPF. Acute expansion of total body water (including plasma volume) also had little effect on GFR and ERPF in conscious Brattleboro rats of either sex (18). One of the few conditions which does recapitulate the renal hemodynamic changes of pregnancy is chronic expansion of total body water produced by continuous administration of arginine vasopressin or oxytocin (reviewed in reference 19). Whether the mechanisms responsible for marked elevation of ERPF and GFR in the two conditions are related, however, is unknown.

Renal innervation is apparently unnecessary for renal hyperfiltration during pregnancy, as the response is also observed in women with renal allografts (20). Baylis and Blantz (21) postulated that suppression of tubuloglomerular feedback activity by plasma volume expansion may contribute to renal vasodilation and hyperfiltration of pregnancy. Pregnancy, however, did not suppress tubuloglomerular feedback in the rat, rather the mechanism was reset at a higher single nephron glomerular filtration rate. These results suggest that the expanded plasma volume of pregnancy is actually sensed as being normal presumably because of increased vascular capacity.

Ultimately, renal vasodilation in pregnancy is likely to be under endocrinologic control. Unfortunately, so many hormonal systems change that it is difficult to know which ones deserve investigation in this regard. Nevertheless, when administered to nonpregnant women, progesterone significantly increased ERPF and GFR $(22,23)$. Prolactin has also been considered, but the reports of its effects on ERPF and GFR in rats are conflicting, and further investigation is needed (reviewed in reference 7). Placental lactogen, a hormone that has considerable homology with prolactin, may also warrant study. On the other hand, a maternal factor or hormone is apparently sufficient, because increases in ERPF and GFR have been documented in pseudopregnant rats $(24,25)$. By mating a female rat which a vasectomized male, pseudopregnancy, a condition which physiologically mimics the first half of gestation but lacks fetoplacental development, is produced.

Other possible candidates include various endothelial factors such as vasodilatory PGs, endothelium-derived relaxing factor or nitric oxide, and endothelium-derived hyperpolarizing factor. The potential role of PGs has been tested in gravid animal models. Gestational increases in ERPF and/or GFR were unaffected by administration of cyclooxygenase inhibitors to conscious pregnant rabbits $(26)$ and rats $(4,5)$. Moreover, measurements of vasodilatory PG production by relevant renal tissues ex vivo failed to show increased synthesis by the tissues from pregnant animals $(6,27)$. A role for vasodilatory PGs in the gestational elevation of ERPF and GFR, therefore, seems doubtful. On the other hand, a role for another endotheliumderived vasodilator, nitric oxide, and its second messenger, cGMP (7-9), is possible and addressed by the current investigation. Alternatively, it may not be change of endothelial function alone that mediates renal vasodilation during pregnancy but rather modification of vascular smooth muscle may contribute (28).

Various isoforms of nitric oxide synthase have been localized to renal tubules and blood vessels by immunohistochemistry or after microdissection by PCR (reviewed in reference 29). Thus, the potential for nitric oxide modulation of glomerular and tubular function is established. By acutely administering nitric oxide synthase inhibitors (analogues of L-arginine), numerous investigators have documented the importance of nitric oxide in the maintenance of renal vascular tone in nongravid animals, including the conscious rat (e.g., 30, 31 ). Nitric oxide was also found to modulate vascular tone and GFR in the isolated perfused rat kidney (32). Renal vasoconstriction produced by acute nitric oxide synthase inhibition was reversible by Larginine (30-32) and not related to endogenous angiotensin II 
$(33,34)$. Whether renal vasoconstriction produced by acute nitric oxide synthase inhibition is dependent on renal nerve activity remains controversial (34-36). Renal micropuncture studies in anesthetized rats showed that intravenous administration of NMA leading to large increases of blood pressure produced a rise in both preglomerular and efferent arteriolar resistances as well as in glomerular hydrostatic pressure and a fall in the glomerular capillary ultrafiltration coefficient $\left(K_{\mathrm{f}}\right)$; in one study, glomerular plasma flow declined relatively more than single nephron glomerular filtration rate (37), whereas in another, single nephron GFR did not fall at all (38). Lower dosages of NMA administered directly into the renal artery leading to smaller increases of blood pressure produced a rise only in preglomerular arteriolar resistance and a fall in $K_{\mathrm{f}}$ such that a greater decline was noted for single nephron GFR relative to glomerular plasma flow in this setting (37). Nitric oxide was also reported to modulate vascular tone of isolated perfused juxtamedullary interlobular, afferent, and efferent arterioles from the rat $(39,40)$.

In the present study, three different dosages of NAME were administered, leading to elevations of MAP ranging from 5 to $50 \mathrm{mmHg}$. The changes in renal function of virgin rats were similar to those previously reported $(30,31)$. That is, marked renal vasoconstriction concommittant with a decline in ERPF, relative maintenance of GFR, and a steep rise in filtration fraction were observed (Figs. 1 and 2, and see Results). Identical findings were obtained with NMA (Table II and Fig. 3). For the midterm pregnant rats, however, GFR also declined during nitric oxide synthase blockade (Figs. 1-3 and Table II). Despite this decline in GFR, a rise in filtration fraction comparable with virgin rats was observed, because ERPF declined relatively more than GFR in the gravid animals (Figs. 1-3 and Table II, and see Results). Although micropuncture experiments are clearly needed, these data suggest that the nitric oxide synthase inhibitors affected the glomerular microcirculation differently in virgin and midterm pregnant rats. Whereas efferent arteriolar constriction was most notable in virgin rats leading to relative maintenance of GFR despite a decline in ERPF, preglomerular arteriolar constriction was most notable in gravid animals as GFR was not maintained in the face of a decline in ERPF. Alternatively, $K_{\mathrm{f}}$ may have been decreased to a greater extent in the pregnant rats. In either case, the finding that ERPF and GFR were equalized in gravid and virgin rats by nitric oxide synthase blockade strongly suggests that nitric oxide mediates gestational hyperfiltration and renal vasodilation. Nitric oxide may act both directly on the renal microcirculation and, possibly, indirectly by modulating renal sympathetic nerve activity (34-36), thereby dilating the renal arterioles in pregnancy. An indirect effect by modulation of renal sympathetic activity seems less likely, however, because gestational hyperfiltration is apparently independent of renal innervation (at least in women) (20).

To approximate the extent of nitric oxide synthase blockade in the midterm pregnant and virgin rats, we measured aortic and renal cortical cGMP content ex vivo as a bioassay of tissue nitric oxide synthase activity (41). We found that the low dose of NAME $(2 \mu \mathrm{g} / \mathrm{min})$, which produced only modest increases of blood pressure, consistently reduced tissue cGMP content to comparable levels in the two groups of rats (Table IV). Thus, comparable blockade of nitric oxide synthase was most likely achieved by our infusion protocol. On the other hand, higher doses of NAME and NMA, which markedly increased blood pressure, failed to consistently reduce tissue cGMP content in either group of rats. Because atrial natriuretic hormone release is augmented by increases of blood pressure, this finding may relate to the overriding effect of the hormone on tissue particulate guanylate cyclase (41). At the higher doses of nitric oxide synthase inhibitor, therefore, tissue cGMP content is apparently no longer a reliable index of nitric oxide synthase activity.

Of additional interest are the data showing that basal levels of renal and aortic cGMP content are not significantly different between the virgin and gravid rats (Table IV). This observation corroborates our previous work in which we systematically measured basal cGMP of aortic tissue in the presence and absence of endothelium, hemoglobin, phosphodiesterase inhibitors, and L-arginine (42). No differences in cGMP content between virgin and gravid rats were detected in any of these treatments. We concluded that basal production of nitric oxide synthase is comparable in aortae from virgin and pregnant rats at least when assessed by cGMP bioassay ex vivo, and the inducible isozyme is not expressed during gestation. Thus, the continuous presence of some factor in vivo may be required for enhanced nitric oxide production by aorta and kidney cortical tissues in gravid rats. Alternatively, because renal cortical tissue is mainly comprised of tubules, augmented nitric oxide production by the microvasculature affecting hemodynamic changes may not have been detectable by our bioassay. Conceivably, enhanced biosynthesis of nitric oxide and cGMP during rat gestation may effect long-lived modification of vessel function, which can persist for some time despite reduction of endothelial nitric oxide production and vascular cGMP content to nonpregnant levels.

To exclude the possibility that renal vasoconstriction per se led to the normalization of renal function in gravid rats by a nonspecific mechanism, we also tested the response to angiotensin II. In contrast to the vasoconstriction produced by nitric oxide synthase inhibitors, midterm pregnant rats were less responsive to angiotensin II than virgin animals, such that the baseline differences in renal function between the two groups of rats were actually enhanced during infusion of the hormone (Table III and Fig. 4). Attenuation of renal vascular reactivity to angiotensin II has been previously reported for conscious pregnant rats during late pregnancy (4) and in conscious gravid rabbits (43), although not all investigators have reported an attenuated response (44). The decrement of GFR in response to angiotensin II was also diminished in pregnant women of 26-35 gestational weeks (45). We speculate that the attenuation of renal vascular responses to angiotensin II during rat gestation is mediated by nitric oxide. [We previously reported that it is not dependent on vasodilatory prostaglandins (4).] The resistance to the systemic pressor effect of angiotensin II is not consistently observed until late gestation in rats (4).

To our knowledge, the contribution of nitric oxide to reduced vascular tone and increased blood flow in other organs during pregnancy has not been investigated. Teleologically speaking, reduced vascular tone in nonreproductive vascular beds such as the kidney serves to reduce total systemic vascular resistance and blood pressure, which stimulates sodium appetite and thirst as well as renal retention of sodium and water (46). These factors allow for expansion of plasma volume, which in turn abets the increase of cardiac output and ultimately of oxygen and nutrient delivery to the fetus and placenta. In previous work, we identified increased biosynthesis of nitric oxide and cGMP during gestation in rats (7-9). In the present study, we provide evidence that nitric oxide mediates the reduction in renal vascular resistance during pregnancy in this species. If 
this finding pertains to women, then a deficiency of nitric oxide production may account for the reductions in ERPF and GFR observed in preeclampsia (see reference 47 for review). Clearly, further investigation is needed to identify the stimulus for enhanced biosynthesis of nitric oxide in the kidney during gestation and to determine whether nitric oxide synthase protein and mRNA expression are increased and, if so, by which renal anatomical structures.

\section{Acknowledgments}

We thank Monique Mosher for expert preparation of the figures.

This work was supported by a Flinn Foundation Investigator Award, the 8th Mallinckrodt Scholar Award, and a grant from the National Institutes of Health (RO1 HD-30325). L. A. Danielson was a recipient of a graduate student stipend from the National Institutes of Health Minority Institutional Research Training Grant (5-T32-HL07736).

\section{References}

1. Conrad, K. P. 1992. Renal changes in pregnancy. Urol. Ann. 6:313-340. 2. MacGillivray, I., G. A. Rose, and B. Rowe. 1969. Blood pressure survey in pregnancy. Clin. Sci. 37:395-407.

3. Conrad, K. P. 1984. Renal hemodynamics during pregnancy in chronically catheterized, conscious rats. Kidney Int. 26:24-29.

4. Conrad, K. P., and M. C. Colpoys. 1986. Evidence against the hypothesis that prostaglandins are the vasodepressor agents of pregnancy. J. Clin. Invest. 77:236-245.

5. Baylis, C. 1987. Renal effects of cyclooxygenase inhibition in the pregnant rat. Am. J. Physiol. 253:F158-F163.

6. Conrad, K. P., and M. J. Dunn. 1987. Renal synthesis and urinary excretion of eicosanoids during pregnancy in rats. Am. J. Physiol. 253:F1197-F1205.

7. Conrad, K. P. 1987. Possible mechanisms for changes in renal hemodynamics during pregnancy: studies from animal models. Am. J. Kidney Dis. 9:253259.

8. Conrad, K. P., and K. A. Vernier. 1989. Plasma level, urinary excretion, and metabolic production of cGMP during gestation in rats. Am. J. Physiol. 257:R847-R853.

9. Conrad, K. P., G. M. Joffe, H. Kruszyna, R. Kruszyna, L. G. Rochelle, R. P. Smith, J. E. Chavez, and M. D. Mosher. 1993. Identification of increased nitric oxide biosynthesis during pregnancy in rats. FASEB (Fed. Am. Soc. Exp. Biol.) J. 7:566-571.

10. Conrad, K. P., M. Gellai, W. G. North, and H. Valtin. 1986. Influence of oxytocin on renal hemodynamics and electrolyte and water excretion. Am. J. Physiol. 251:F290-F296.

11. Führ, J., J. Kaczmarczyk, and C. D. Krüttgen. 1955. Eine einfache colorimetrische Methode zur Inulinbestimmung für Nieren-Clearance-Untersuchungen bei Stoffwechselgesunden und Diabetikern. Klin. Wochenschr. 33:729-730.

12. Smith, H. W., N. Finkelstein, L. Aliminosa, B. Crawford, and M. Graber. 1945. The renal clearances of substituted hippuric acid derivatives and other aromatic acids in dog and man. J. Clin. Invest. 24:388-404.

13. Bradford, M. 1976. A rapid and sensitive method for the quantification of microgram quantities of protein utilizing the principal of protein-dye binding. Anal. Biochem. 72:248-254. NJ.

14. Zar, J. H. 1984. Biostatistical Analysis. Prentice Hall, Englewood Cliffs,

15. Lindheimer, M. D., and A. I. Katz. 1991. The kidney and hypertension in pregnancy. In The Kidney. B. M. Brenner and F. C. Rector, (editors). W. B. Saunders, Philadelphia, PA.

16. Atherton, J. C., J. M. Dark, H. O. Garland, M. R. A. Morgan, J. Pidgeon, and S. Soni. 1982. Changes in water and electrolyte balance, plasma volume and composition during pregnancy in the rat. J. Physiol. (Lond.). 330:81-93.

17. Reckelhoff, J. F., L. Samsall, and C. Baylis. 1989. Failure of an acute $10-15 \%$ plasma volume expansion in the virgin female rat to mimic the increased glomerular filtration rate (GFR) and altered glomerular hemodynamics seen at midterm pregnancy. Clin. Exp. Hypertens. B8:533-549.

18. Gellai, M., J. H. Silverstein, J.-C. Hwang, F. T. LaRochelle, Jr., and H. Valtin. 1984. Influence of vasopressin on renal hemodynamics in conscious Brattleboro rats. Am. J. Physiol. 246:F819-F827.

19. Conrad, K. P., M. Gellai, W. G. North, and H. Valtin. 1993. Influence of oxytocin on renal hemodynamics and sodium excretion. Ann. NY Acad. Sci. 689:346-362.

20. Davison, J. M. 1985. The effect of pregnancy on kidney function in renal allograft recipients. Kidney Int. 27:74-79.

21. Baylis, C., and R. C. Blantz. 1985. Tubuloglomerular feedback activity in virgin and 12-day-pregnant rats. Am. J. Physiol. 249:F169-F173.

22. Chesley, L. C., and I. H. Tepper. 1967. Effects of progesterone and estrogen on the sensitivity to angiotensin II. J. Clin. Endocrinol. Metab. 27:576581 .

23. Atallah, A. N., J. A. G. Guimaraes, M. Gebara, D. R. Sustovich, T. R. Martinez, and L. Camano. 1988. Progesterone increases glomerular filtration rate, urinary kallikrein excretion and uric acid clearance in normal women. Braz. J. Med. Biol. Res. 21:71-74.

24. Atherton, J. C., D. Bu'lock, and S. C. Pirie. 1982. The effect of pseudopregnancy on glomerular filtration rate and salt and water reabsorption in the rat. $J$. Physiol. (Lond.). 324:11-20.

25. Baylis, C. 1982. Glomerular ultrafiltration in the pseudopregnant rat. Am. J. Physiol. 234:F300-F305.

26. Venuto, R. C., and A. J. M. Donker. 1982. Prostaglandin $E_{2}$, plasma renin activity, and renal function throughout rabbit pregnancy. J. Lab. Clin. Med. 99:239-246.

27. Brown, G. P., and R. C. Venuto. 1990. Eicosanoid production in rabbit vascular tissues and placentas. Am. J. Physiol. 258:E418-E422.

28. Conrad, K. P., S. A. Barrera, P. A. Friedman, and V. M. Schmidt. 1991. Evidence for attenuation of myo-inositol uptake, phosphoinositide turnover, and inositol phosphate production in aortic vasculature of gravid rats. J. Clin. Invest. 87:1700-1709.

29. Bachmann, S., and P. Mundel. 1994. Nitric oxide in the kidney: synthesis, localization and function. Am. J. Kidney Dis. 24:112-129.

30. Gardiner, S. M., A. M. Compton, T. Bennett, R. M. J. Palmer, and S. Moncada. 1990. Control of regional blood flow by endothelium-derived nitric oxide. 15:486-492.

31. Baylis, C., P. Harton, and K. Engels. 1990. Endothelial derived relaxing factor controls renal hemodynamics in the normal rat kidney. J. Am. Soc. Nephrol. 1:875-881.

32. Radermacher, J., B. Klanke, H.-J. Schurek, H. F. Stolte, and J. C. Frölich. 1992. Importance of NO/EDRF for glomerular and tubular function: studies in the isolated perfused rat kidney. Kidney Int. 41:1549-1559.

33. Baylis, C., K. Engels, L. Samsell, and P. Harton. 1993. Renal effects of acute endothelial-derived relaxing factor blockade are not mediated by angiotensin II. Am. J. Physiol. 264:F74-F78.

34. Pucci, M. L., L. Lin, and A. Nasjletti. 1992. Pressor and renal vasoconstrictor effects of $N^{\mathrm{G}}$-nitro-L-arginine as affected by blockade of pressor mechanisms mediated by the sympathetic nervous system, angiotensin, prostanoids and vasopressin. J. Pharmacol. Exp. Ther. 261:240-245.

35. Lacolley, P. J., S. J. Lewis, and M. J. Brody. 1991. Role of sympathetic nerve activity in the generation of vascular nitric oxide in urethane-anesthetized rats. Hypertension (Dallas). 17:881-887.

36. Sakuma, I., H. Togashi, M. Yoshioka, H. Saito, M. Yanagida, M. Tamura, T. Kobayashi, H. Yasuda, S. S. Gross, and R. Levi. 1992. $N^{\mathrm{G}}$-methyl-L-arginine, an inhibitor of L-arginine-derived nitric oxide synthesis, stimulates renal sympathetic nerve activity in vivo. 70:607-611.

37. Deng, A., and C. Baylis. 1993. Locally produced EDRF controls preglomerular resistance and ultrafiltration coefficient. Am. J. Physiol. 264:F212-F215.

38. Zatz, R., and G. De Nucci. 1991. Effects of acute nitric oxide inhibition on rat glomerular microcirculation. Am. J. Physiol. 261:F360-F363.

39. Ohishi, K., P. K. Carmines, E. W. Inscho, and L. G. Navar. 1992. EDRFangiotensin II interactions in rat juxtamedullary afferent and efferent arterioles. Am. J. Physiol. 263:F900-F906.

40. Imig, J. D., and R. J. Roman. 1992. Nitric oxide modulates vascular tone in preglomerular arterioles. Hypertension (Dallas). 19:770-774.

41. Arnal, J.-F., L. Warin, and J.-B. Michel. 1992. Determinants of aortic cyclic guanosine monophosphate in hypertension induced by chronic inhibition of nitric oxide synthase. J. Clin. Invest. 90:647-652.

42. Whittemore, S. L., M. K. McLaughlin, S. T. Davidge, and K. P. Conrad. 1994. Effect of pregnancy on aortic cGMP production and vasorelaxation in the rat. Hypertension in Pregnancy. 13:227-244.

43. Brown, G. P., and R. C. Venuto. 1991. Renal blood flow response to angiotensin II infusions in conscious pregnant rabbits. Am. J. Physiol. 261:F51F59.

44. Masilamani, S., and C. Baylis. 1992. J. Am. Soc. Nephrol. 3:566. (Abstr.) 45. Chesley, L. C., R. M. Wynn, and N. I. Silverman. 1963. Renal effects of angiotensin II infusions in normotensive pregnant and nonpregnant women. Circ. Res. XIII:232-238.

46. Gilson, G. J., M. D. Mosher, and K. P. Conrad. 1992. Systemic hemodynamics and oxygen transport during pregnancy in chronically instrumented, conscious rats. Am. J. Physiol. 263:H1911-H1918.

47. Chesley, L. C., and G. M. Duffus. 1971. Preeclampsia, posture and renal function. 38:1-5. 